Original Article

\title{
The role of supply vessels in offshore logistics
}

\author{
Bjørnar Aas*, Øyvind Halskau Sr and Stein W. Wallace \\ Molde University College, The Norwegian School of Logistics, PO Box 2110, \\ NO-6402, Molde, Norway. \\ E-mail: bjornar.aas@himolde.no \\ * Corresponding author.
}

\begin{abstract}
Oil companies are gradually becoming more focused on optimizing their upstream logistics. However, little research regarding upstream logistics has been published. We argue that more research would be beneficial and that more attention must be given to one of the largest cost elements in the upstream chain - the supply vessels. We explore the supply vessel as a means of transport and carry out a logistics analysis based on their use on the Norwegian continental shelf. Carrying capacity, sailing, loading and unloading capabilities are established as the main features of a supply vessel. Thereafter we discuss relevant logistical trade-offs within and among these features, and also in relation to the environment the vessels operate in. This elaboration clearly shows the complexity involved when searching for the 'optimal' supply vessel. The analysis also indicates the design and logistics system features that should be challenged in the future. We believe that the findings in this article will be of considerable value for both practitioners and academics.
\end{abstract}

Maritime Economics \& Logistics (2009) 11, 302-325. doi:10.1057/mel.2009.7

Keywords: oil industry; supply vessels; logistics; design

\section{Introduction}

Norway's oil and gas production takes place offshore. In order to ensure continuous production, the offshore installations need to be supplied regularly. The only way to do this is by using supply vessels that represent one of the largest cost elements in the upstream supply chain of oil and gas installations. 
Supply vessels are usually chartered rather than owned by the oil companies. However, the oil companies decide the use of the vessels. In practice, this means that activities such as scheduling and routing are the responsibility of the oil company. In the literature, this type of logistics planning problem is often mentioned as a vehicle routing problem (Toth and Vigo, 2002). Such problems are usually solved by using optimization techniques or simulation. For a review of the literature focusing on ship routing and scheduling, see Christiansen et al (2004).

Presently such approaches are not commonly used in the oil and gas industry when planning for the use of supply vessels. We believe that there are two main reasons for this. First, the formal logistics competence of the logistics planners within the oil companies has traditionally been low. Second, logistics research with focus on supply vessels and their routing has not been given much attention in the past. The more deep-rooted reason for this is that logistics is an important activity for oil companies but it is not a core activity. Consequently there is a low level of formal knowledge about the supply vessel and its properties, particularly outside the industry.

Since supply vessels are so important in the offshore oil and gas industry, it would be beneficial to address this shortcoming. Routing problems related to other industries have been explored for decades and it is reasonable to believe that there is something to be learnt from this for the oil companies. This view is shared by several oil companies and such research has gradually been put on the agenda. The concept of 'integrated operations' has become a hot topic in the industry (IOCENTER, 2008). Additionally, it is obvious that the oil companies hold a lot of valuable tacit knowledge that could be of value for academics.

A few articles have been published about supply of offshore installations. However, the focus has been mainly on the routing problem, not the supply vessel itself. The first article about this problem was published in 2000 by Fagerholt and Lindstad where they proposed an optimal routing policy for the Norwegian Sea given that all installations were open round the clock (Fagerholt and Lindstad, 2000). However, their focus was on the routing aspects and not on how the design of the supply vessel and its ability to execute the transport job affect logistics. In Aas et al (2007) and Gribkovskaia et al (2007) the focus was also on finding the best route given the availability of 'average sized' supply vessels. No other logistical features were considered. To the best of our knowledge, there have not been any other published articles about the use of supply vessels and associated logistics problems.

Hence, the approaches taken so far have described supply vessels in a simplified way and focused on routing alone. However, a different approach is needed if the aim is to find a vessel that is better suited to the task, or new vessel types that can enter into a fleet of vessels and then contribute to better 
fleet performance. A more in-depth knowledge about the vessel itself, the job that it performs, and how different vessels work together as a fleet, would be needed; see Schneekluth and Bertram (1998).

We agree with this view, as finding a good fleet composition (meaning both determining the fleet size and the composition of a heterogeneous fleet) is essential in logistics planning. Hence, there are some basic questions that must be answered regarding supply vessels:

- What kind of means of transport is a supply vessel and what kind of transport jobs is it carrying out?

- What features of the supply vessel, and what parts of the environment, constitute hard or soft limitations for the execution of the logistics?

- What are the relevant financial trade-offs?

Consequently, this article is about fleet design. The main target group is academics working with (maritime) transport research and routing problems. We wish to contribute to an increased understanding and awareness of what offshore supply implies and what properties this means of transport should have. Hopefully, this will lead to more research related to the design and routing of supply vessels, producing more cost-efficient supply of offshore installations.

The rest of this article is organized as follows. We start by presenting our research design and methodology, followed by a description of the typical logistics chain where the supply vessel operates. After that, we explore the use of supply vessels on the Norwegian continental shelf (NCS), and elaborate more thoroughly on the main logistical features of a supply vessel. Finally, in the last section, we treat the design and fleet composition opportunities that influence the logistics and their associated logistical trade-offs. Conclusions and suggestions for further research are also presented in the last section.

\section{Research Design and Methodology}

The research idea arose while working with different research projects related to upstream logistics within a large oil and gas company, StatoilHydro ASA (StatoilHydro ASA, 2008), over the past 6 years. StatoilHydro is the world's third largest net seller of crude oil, the leading player on the NCS and its foremost industrial architect. During this time, the lack of proper academic descriptions of supply vessels and associated logistics challenges became evident.

We believe that our long cooperation with StatoilHydro has provided us with the necessary knowledge to address some of these shortcomings. This 
knowledge builds on on-site observations, informal talks, interviews, analyses of internal company documents and the supervision of several relevant MSc projects. Additionally, we have interviewed designers of supply vessels in a major supply vessel design company and supply vessel skippers.

Taking advantage of the close cooperation with StatoilHydro, we have limited ourselves to focus on the geographical area where this oil company has its main activity; the NCS, to gain a best possible understanding of our research issue. Despite this geographical limitation, as far as we can see, there is nothing indicating that the findings and conclusions drawn in this article would be different if we had focused on other geographical areas.

Furthermore, most of our understanding is based on the cooperation with StatoilHydro and it could be that other oil companies use supply vessels differently or have different opinions about what are the relevant and important challenges and financial trade-offs.

\section{Upstream Logistics}

\section{Offshore drilling and production units (offshore installations)}

In the oil and gas industry 'downstream logistics' is defined as bringing oil and gas to onshore customers while 'upstream logistics' is defined as supplying the offshore drilling and production units with the necessary supplies. See Aas et al (2008) for more about the upstream chain.

Important issues in upstream logistics are to support offshore activities so that these can be carried out as planned and in a cost-efficient way. To be able to operate from remote locations, offshore drilling and production units need different types of support services that are provided by specialized vessels. Examples of such vessels are Anchor Handling Vessels, Offshore Supply Vessels (OSVs), Crew Boats and Standby/Rescue vessels, see Barret (2005). We focus on OSVs, also called Platform Supply Vessels or just 'supply vessels' as called here.

The end customers for the supply vessels are the offshore drilling and production units. The high value of the production, and the high cost of delaying offshore operations dictate the design of the upstream chain.

There are many types of offshore drilling and production units representing different logistical needs. It is common to distinguish between two types of units. First we have units that are mainly producing (but might also be drilling) and stay at the same position for a longer period, such as (production) platforms or production ships. Second, we have those moving around on commission, solely for exploration, called exploration (or wildcat) rigs/ships. The 
size of offshore drilling and production units can vary from small, unmanned units to large constructions, in which several hundred workers are needed onboard. Consequently, the need for supplies to support daily operations (like food, clothes and so on), and the amount and type of equipment needed, for instance to carry out drilling operations (for example, drill pipes and casing), will vary significantly. For more information about different types of offshore units and their needs, see Hyne (2001).

As our focus in this research is the supply vessel, and not a particular type of offshore unit, we must in our analysis take into account that there exists a large variety of offshore units. However, it is beyond our goal to describe in detail the different types of offshore units. Therefore, for simplicity, we will hereafter name all kinds of offshore drilling and production units as 'offshore installations.

In general, installations that are drilling have more fluctuating and uncertain demand patterns for supplies than producing installations. The reason for this is the complex nature of offshore drilling operations. The demand uncertainties are characterized by uncertain volumes (for example, how much casing will be needed) and due dates. Producing installations usually have a smoother and more predictable demand. However, a certain level of uncertainty is always present. Naturally, these uncertainties transmit to the whole supply chain and make the planning and execution of the logistics quite challenging.

Installations do not only need to receive supplies. There is also a need for return transport and the directional balance is good. Most of the returned cargos are empty load carriers, waste, rented equipment and excess back-up equipment. In general, offshore installations have a rather limited storage capacity, and thus it is important to have rather frequent visits to avoid a shortage of supplies or a buildup of return cargo. Much of the equipment, especially specialized equipment used in well and drilling operations, is rented with high daily rates; hence it is also financially important to return such equipment quickly.

Often installations are located in clusters. The main reasons for this are that discoveries of oil and gas are usually naturally limited geographically and that economies of scale related to both the upstream and downstream part of the chain make it more beneficial for the oil companies to cluster offshore production facilities. However, this leads to a clustering of heterogeneous installations with regard to their demands and storage capacities. When supplying such a cluster by the same upstream chain, the challenge is to design an upstream chain that is both lean and agile. Although the main focus of lean supply is on reducing costs (Lamming, 1993), the main focuses of agile supply are high responsiveness and flexibility (Christopher, 2000). 


\section{Supply vessels}

Supply vessels are a fairly new category of ships. The need for this type of vessel arose with the start of the oil exploration activity in the Gulf of Mexico in the mid 1950s. Since then, the use of supply vessels has been spread worldwide. The gradual exploration of more demanding areas has contributed to an evolution of the supply vessels. See Gibson (2007) for more about the historical development of supply vessels.

Today the worldwide supply vessel fleet consists of more than 1000 vessels operating mainly in the Gulf of Mexico, the North Sea (approximately 15 per cent), West Africa, Asia-Pacific, the Middle East, Brazil and other miscellaneous locations in Latin America (Barret, 2005).

Basically, supply vessels are used to transport supplies back and forth between the supply base and the installations. Supplies can be divided in two main categories: deck cargo and bulk cargo. Deck cargo is everything transported on the deck of the supply vessel whereas bulk cargo is everything transported in the below deck tanks of the supply vessel. These storage facilities are mirrored on the offshore installations. They store containers on deck and have tanks for bulk. There are capacity restrictions for both types of goods on installations as well as vessels.

It is not unusual that supply vessels also have other duties concerning, for instance, fire-extinguishing or oil-spill preparedness. Such tasks are important, but in this article we will only focus on the primary task of the supply vessel as a means of transport.

A supply vessel is a multi-task vessel and has to be designed for many different purposes. This is contrary to most other ships used worldwide, which commonly have one type of hold usually transporting one type of cargo, see Alderton (1995, p. 22). A consequence of being a multi-task vessel is that the determination of the best design with regard to economy of scale (in terms of size) and economy of scope (specialization) effects becomes more challenging.

In general, the geographical location where the offshore activity takes place is an important indicator of the choice of supply vessel. Factors like weather conditions, the amount of equipment needed and the distance from the shore are important for what properties the vessel should have.

Most oil companies charter supply vessels on the supply vessel market. The rate they pay depends upon many factors such as the features of the vessel, the length of the charter, the supply/demand balance at the time the charter is signed and the location of the vessel. In addition to paying rent, it is common that the oil company pays for fuel, bunkers oil and harbour dues. All other costs are covered by the shipowner.

(C) 2009 Palgrave Macmillan 1479-2931 Maritime Economics \& Logistics Vol. 11, 3, 302-325 
Both short-term (spot) and long-term charters are thus available on the market. It is important for the shipowners that the vessels are chartered out at all time to ensure a steady cash flow. Consequently, to build a tailor-made vessel, a shipowner needs to be certain that there is a long-term charter. Vessels built for trading the spot-market (built on speculation) are usually designed to be amenable to a wide range of potential clients, often worldwide.

The cost of chartering and operating a supply vessel is one of the largest logistics cost elements in the upstream chain. Consequently, getting the needed capacity at the lowest possible rate, and maximizing the utilization of the vessels are important objectives for the oil companies. By 'good utilization' we mean maximizing the number of loaded days at sea and the utilization of a vessel's transport capacity on each trip. Still, because of the enormous shortage costs that can arise if an installation's needs are not satisfied, the vessel's or fleet's capability to meet the demand for transport capacity at all times is a paramount objective.

\section{The Norwegian Continental Shelf}

The areas where oil and gas exploration and production are taking place on the NCS are illustrated in Figure 1.

Today the major oil and gas producing areas are the northern and southern parts of the North Sea plus the Norwegian Sea. The first area to be developed was the southern part of the North Sea where Ekofisk came on stream in 1971. The Norwegian Sea is the smallest and last to be developed, and production started in 1993. Today, a total of 70 fields are developed on the NCS (Norwegian Petroleum Directorate, 2007).

Even though the oil and gas companies on the NCS aim to gradually install more underwater production units (infrastructure placed on the seabed), together with more remote controlled surface installations, the need for supply vessels is expected to remain high for many more years to come. Today, approximately 140 supply vessels are operating on the NCS (R.S. Platou and Offshore, 2008).

All the installations in each of the areas are supplied from one or two dedicated supply bases. The particular harsh weather conditions on the NCS, combined with the gradually more demanding offshore activities taking place, makes the supply of the installations very challenging.

The world fleet of supply vessels consists of a variety of vessels where a large proportion was built in the late 1970s or early 1980s (Barret, 2005). However, a majority of the vessels operating on the NCS are rather new and modern. An important reason for this is that many of the oil companies there 


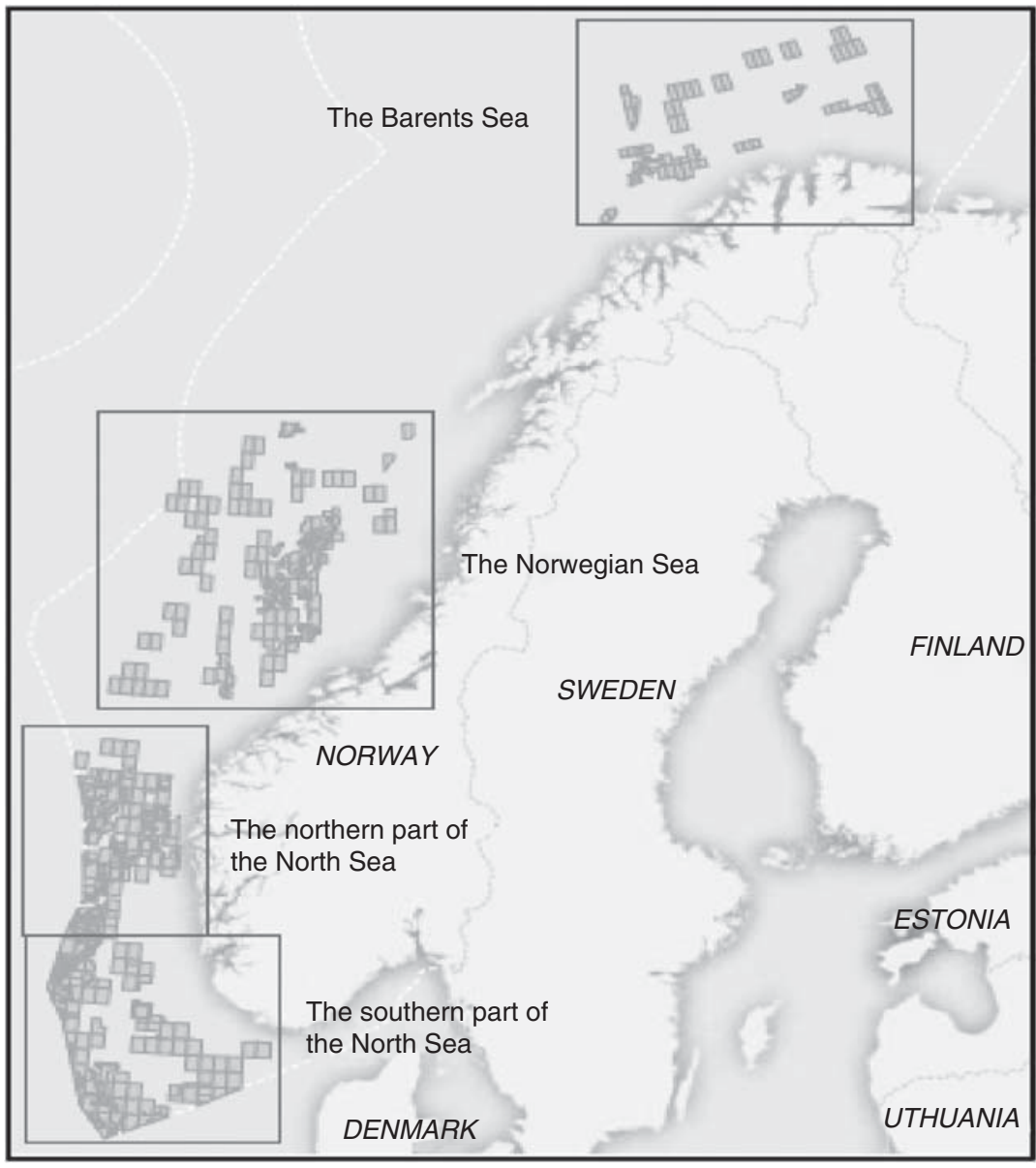

Figure 1: The Norwegian continental shelf (Norwegian Petroleum Directorate, 2007).

want vessels that represent the state-of-the-art when it comes to cost-efficiency and aspects of health, safety and environment. Another important reason is that in the past few years high oil prices have led to increased exploration activity and consequently resulted in an increased demand for more supply vessels.

The increased demand has been rather well covered by the market. However, daily rates have increased (Offshore Shipbrokers Limited, 2008) and there has recently been a tendency towards signing longer contracts (R. S. Platou and Offshore, 2008). Several new vessels have also entered the market and many more will do so in the years to come (R. S. Platou and Offshore, 2008). 
Many of the most modern and innovative supply vessels in the world are designed and produced within the framework of the Norwegian maritime cluster (see Benito et al, 2003, for more information on this cluster). Shipowners like Bourbon Offshore Norway (Bourbon Offshore Norway, 2008) and Eidesvik Shipping (Eidesvik Shipping, 2008) have been at the forefront when it comes to ordering innovative supply vessels that have been chartered for use on the NCS. Examples of modern and innovate supply vessels are Eidesvik's Vik-Sandvik designed (Vik-Sandvik, 2008) 'Avant' vessels with aft accommodation, and its liquefied natural gas (LNG) vessels. Another example is Bourbon Offshore's X-bow vessel designed by Ulstein Design (Ulstein Group, 2008). All these vessels aim to be more environmentally friendly by focusing on reduced fuel emissions and zero spills by meeting the DNV Clean Design requirements (DNV, 2008).

Modern vessels are rather expensive to chart ${ }^{1}$ and it has gradually become more important for oil companies operating on the NCS to maximize the utilization of the chartered vessels. One important reason for this is that many areas have turned into 'mature' areas. Mature areas are characterized by familiar geology, well-developed infrastructure, falling production rates and increasing unit costs (Norwegian Petroleum Directorate, 2007). To be able to maximize the exploitation of such fields, it is important to keep the logistics costs low (Ministry of Petroleum and Energy, 2004).

The oil company that operates an installation is also responsible for the logistics including the scheduling and routing of the supply vessels. The larger oil companies are usually carrying out this by themselves; however, cooperation agreements exist. There are also some examples of outsourcing. This topic is discussed by Aas et al (2008).

In order to obtain a good utilization of the vessels, the oil companies usually attempt to serve several installations using the same vessel. This is particularly cost-effective when several installations naturally form a cluster. In the North Sea, a Hub-and-Spoke distribution model (where consolidation is used as a means to achieve economies of scale) is also used by the oil company ConocoPhillips (ConocoPhillips, 2008a). There are also a few 'supply vessel pools' meaning that several oil companies share the use of the same supply vessels. This is, for instance, practiced in the Norwegian Sea where a supply vessel pool is presently operating three vessels. The Norwegian government explicitly urges this type of cooperation as a part of its effort to ensure efficient exploitation of the country's oil and gas resources (Ministry of Petroleum and Energy, 2004).

Most installations on the NCS are visited by supply vessels 1-3 times a week. Usually fixed routes are used as starting point for planning. However, because of uncertainties related to demand and weather, routes change 
frequently. The uncertainties constitute a major challenge for scheduling and routing and make it difficult to obtain a high utilization of the supply vessels based on a deterministic planning approach.

\section{Supply Vessel Features}

In this section we will focus on what we consider are the main logistical features of a supply vessel. Our approach is inspired by general considerations within ship design; see, for example, Schneekluth and Bertram (1998).

We will also focus on how the environment imposes limitations and makes demands on the design of the supply vessel, before we turn to the consequences and relevant logistical trade-offs in the next section.

For more detailed technical information about supply vessels and practical aspects of supply vessel operations, see Ritchie (2007).

\section{Reliability and operational capability}

A supply vessel is a reliable means of transport. This is of course of great importance considering the significant shortage costs that can occur if the upstream logistics fails.

According to our experience and investigation, supply vessels rarely break down. However, this could vary somewhat between different vessels. Data regarding reliability are regarded by most shipowners as sensitive information, so an exact picture of the present situation is impossible to get.

When a supply vessel is chartered, it is at the disposal of the oil company. This means that it is available 24 hours a day all year round. The only limitations are that the vessel must be allowed to go to harbour every fourth week to rotate crew and that each year a few days are dedicated to maintenance. In practice it is usually not a problem to plan for this. Approximately every second year, a supply vessel is docked to carry out more comprehensive maintenance.

All costs related to repair and maintenance are covered by the shipowner. When the vessel is not operational, charter fee is not received. However, a shipowner is not responsible for any shortage costs that could arise on the installations caused by unpredictable technical problems with the vessel.

\section{Carrying capacity}

Carrying capacity relates to the capability of a supply vessel to carry deck cargo and bulk cargo. Supplies transported on deck are classified as deck cargo 
and supplies transported in tanks underneath the deck are classified as bulk cargo.

\section{Deck cargo}

Deck capacity is given in square metres and, for instance, Offshore Shipbrokers (2008) use the following categories based on deck area: $0-525 \mathrm{~m}^{2}, 526-725 \mathrm{~m}^{2}$ and over $726 \mathrm{~m}^{2}$. A majority of the vessels used on the NCS are in the two latter categories. The deck area is rarely larger than $1000 \mathrm{~m}^{2}$. The largest one is Normand Skipper with a deck area of $1220 \mathrm{~m}^{2}$ (Solstad Offshore, 2008).

The total amount of cargo that a vessel can carry also depends on whether the cargo is loaded at the supply base or offshore. It is more difficult to place containers tightly together offshore than at the supply base.

Most of the deck cargo is packed in offshore containers (generally smaller, more robust and heavier versions of conventional containers), skips (normally used for waste and similar) or baskets (Swire, 2008). Pipes and other heavy constructions are placed directly on the deck. Since all cargo is lifted from the supply vessel's deck onto the installation by crane, and occasionally bumps into each other under this operation, the use of solid load carriers is a necessity.

The fact that most supplies must be packed in offshore containers is a premise for the rest of the supply chain. In particular, this poses challenges for the transport of supplies from suppliers not located at the supply base. Much of the supplies are packed in offshore containers at the suppliers' location and must therefore be transported to the supply base using specialized trucks.

It is not allowed to stack containers or baskets because of safety regulations. It is allowed though to stack skips. However, the use of skips amounts to only a small fraction of the total amount of deck cargo.

Also, because of safety regulations, not all types of cargo can be mixed (The Norwegian Oil Industry Association, 2008). For instance, it might be necessary to have a certain space between two types of cargo. Load segregation is sometimes necessary, but in practice it is not difficult to ensure as it usually only concerns a small part of the cargo.

Sometimes, the strength of the deck is a limitation. Older vessels do not always have the strength to carry, for instance, heavy pipes or other heavy equipment. For newer vessels this is usually not a problem.

\section{Bulk cargo}

A variety of different products, such as methanol, pre-blended drill fluids, brine, water and oil are transported in segregated tanks. All tanks have individual pumps and hoses for discharging. Dry bulk cargo such as cement, barite and bentonite are loaded and discharged by using compressed air. 
During the past few years, the demand for bulk has increased, both with regard to variety and the total amount. This has led to newly built vessels now being equipped with more tanks and automated washing systems ensuring a higher bulk capacity and that the tanks are ready for use soon after the bulk is discharged.

\section{Sailing capability}

Sailing capability relates to the ability of the vessel to sail under different conditions. Bad weather will make it necessary to decrease the speed to not jeopardize cargo and/or crew. High-speed travel in bad weather will make it difficult for the crew to get the needed rest; something that is of utmost importance for safe execution of offshore operations. Furthermore, too high a speed in bad weather could cause damage to the cargo. The ability of the vessel to deal with bad weather is mainly determined by its machinery, propulsion arrangement and hull design. Unlike carrying capacity, which is more of a fixed factor, the sailing capability varies in accordance with the weather conditions and is influenced by the cargo transported.

All supply vessels have what is called an 'economical speed', which is the transit speed that is regarded as most economical under normal operational circumstances. This speed is usually used as a basic input when doing route planning. In other words, the economical speed is used as a foundation when estimating the distance a vessel can sail during a fixed period. The economical speed varies between different vessels, but our research shows that most modern vessels have an economical speed of around 11-13 knots. ${ }^{2}$ The maximal speed is usually around 17-18 knots. To speed up is costly because of the general non-linear relation between speed and fuel consumption for ships Stopford (1997, p. 170).

The difference between economical speed and max speed represents flexibility. Even so, this flexibility is not always available. As mentioned, the sailing capability is, for instance, weather sensitive, thus, bad weather can make it impossible to go fast. Due to the same reasons, it is not always possible to travel even at the economical speed.

\section{Loading/unloading capability}

Traditionally in the shipping literature, loading/unloading capability is associated with ports (Alderton, 1995). This is not the case with supply vessels where the main challenge is to be found at the offshore installations.

There are two main factors that govern the loading/unloading process between a particular installation and a supply vessel: the installation's lifting 
capability and the supply vessel's capability to keep its position. Although the installation's lifting capability is important, we will not focus on this as it is outside the scope of this article.

If the weather is good, all deck cargo and bulk cargo can be loaded/ unloaded simultaneously. Deck cargo is lifted from the deck of the supply vessel to the deck of the installation by the use of cranes mounted on the installations, and bulk is pumped from the tanks on the supply vessel to tanks onboard the installations by the use of hoses. Usually the installations have demands for both categories of supplies.

However, if the weather is bad, offshore loading/unloading can be stopped. So, just as for sailing capability, also the loading/unloading capability is uncertain.

It is the responsibility of the captain of the supply vessel to ensure that loading/unloading is done safely, however, the crane operator and the platform chief also have the authority to stop this operation. In addition, there are regulations with regard to working conditions, which must be met. These relate to factors such as wave height, visibility, wind and currents. An example is that offshore loading/unloading operations carried out on the windward side must be aborted if the significant wave height exceeds $4 \mathrm{~m}$ (The Norwegian Oil Industry Association, 2008). Figure 2 shows the wave heights for a 6-month period at an installation in the Norwegian Sea, illustrating the challenges the wave height limitation poses on logistics planning.

However, the impact of the weather elements varies from installation to installation. The reason might be different geographical locations or whether the installations are equipped with one or several cranes. Several cranes located on different sides increase the chance of being able to operate on the leeward side where the limit for operations is a bit higher (wave height limitation $=4.5 \mathrm{~m})$.

Wave heights, Heidrun installation, The Norwegian Sea

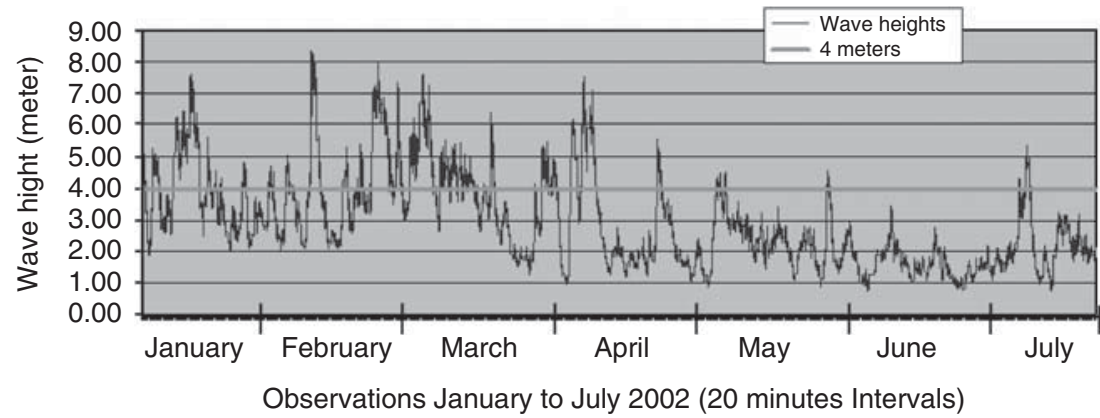

Figure 2: Wave heights based on weather data from StatoilHydro.

314 (C) 2009 Palgrave Macmillan 1479-2931 Maritime Economics \& Logistics Vol. 11, 3, 302-325 
Based on available weather data provided by StatoilHydro's supplier of weather services and information collected from conversations with marine specialists, the wave height stands outs as the major contributor decreasing the offshore loading/unloading capability.

In addition to the hard limitations, there are several supply vessel specific reasons why loading/unloading might be difficult. The capability to cope with the weather elements and keep its position with a high degree of accuracy varies between vessels and is related, for example, to the particular vessel's hull design, propulsion arrangement and machinery power. An example is that it is required that a vessel must not use more than 50 per cent of its machinery power to keep its position alongside the installation (The Norwegian Oil Industry Association, 2008). This is to ensure that the vessel has excess power to handle unforeseen problems. A difference between vessels with regard to, for instance, machinery power causes some vessels to abort loading/unloading operations earlier than others. Also human factors like the experience and risk willingness of the supply vessel skipper play important roles.

During the past decade, vessels that are better at handling bad weather conditions have entered the market. Especially the developments in dynamic positioning systems have been very important; see, for example, Ritchie (2007) for more information. Even so, offshore loading/unloading operations are often stopped by the weather. It is also the situation that bulk operations are a bit more weather sensitive than deck operations. Sometimes this leads to a vessel finishing the loading/unloading of deck cargo, but still must wait or return later to finish the bulk.

Another issue that complicates offshore loading/unloading is that according to safety regulations, it is not allowed to do 'cherry-picking' (The Norwegian Oil Industry Association, 2008). This means that it is prohibited to use a crane to pick a load carrier that is surrounded by other load carriers on all sides. This rule guides the loading and routing of a vessel. In particular, if a vessel is close to full, this rule can make it more difficult to re-route a vessel as most supply vessels are not equipped with cranes for moving deck cargo.

\section{Trade-0ffs and Research 0pportunities}

The purpose of this section is to study the design and fleet composition opportunities that influence the logistics and their associated logistical trade-offs. As we have seen in the previous section, reliability and operational capability are not major issues, so we will therefore focus on the carrying capacity and the sailing capability. 


\section{Searching for the best carrying capacity}

Carrying capacity relates to what, and how much, a vessel or a fleet is able to carry. As explained earlier in the article, oil companies are usually chartering vessels to cover its need for transportation. Thus, to be able to determine the best carrying capacities, circumstances like the demand patterns of the installations, the impact of weather uncertainty, risk of incurring shortage costs and costs related to chartering and operating supply vessels must be considered.

To determine the best fleet composition, the following questions must be answered for each individual supply situation: How large should the total capacity of the vessel or fleet be? And if considering a fleet, how many vessels at which size represent the best fleet configuration?

\section{Determining the total fleet capacity}

If a vessel or a fleet is dimensioned according to the average total demand for transport capacity, because of the level of uncertainty, it will not be able to handle the demand fluctuations without significant and frequent reallocations of cargo in time. In this industry, this is usually not an option because of the use of a lot of expensive rented equipment and such practice in general will increase the probability for shortage costs. Additionally, it is easier for a fleet with excess capacity to handle and recover from larger demand peaks usually caused by bad weather. Furthermore, excess capacity will in many ways make practical operations like loading and unloading and arrangement of cargo easier. It will also make the logistics planning easier. The obvious disadvantage is that excess capacity implies increased rental expenditures and is not an environmentally friendly alternative.

\section{Determining the fleet configuration}

Once capacity has been somehow determined, deciding the number and size of the vessels in the fleet is the next task. According to present day rates (Offshore Shipbrokers Limited, 2008), as in most transport at sea or land, larger vessels give a lower transport unit cost (economies of scale). In addition, we can also regard them as more environmentally friendly. These are also the major arguments for simultaneous transport of deck and bulk cargo. However, they are only valid if high capacity utilization is obtainable. The arguments for using larger vessels could easily diminish in an environment characterized by high demand uncertainty and high shortage costs. The high demand uncertainty often causes a vessel to deviate from its route to cover an urgent need by an installation. The consequences of a large vessel that planned to visit many 
customers deviating from its original route are usually larger than for a smaller vessel. First, a large vessel has more customers assigned to its route so that a rescheduling affects many of them. Second, the probability that a large vessel is in harbour, for example, when something urgently needs to be taken to an offshore installation, is less compared with using more vessels that are smaller. In other words, small vessels are more flexible in dealing efficiently with demand uncertainty under normal operating conditions.

For larger demand peaks, which often happen in front of and immediately after bad weather, and hence often are predictable a day or two ahead of time, experience has shown that a fleet consisting of many large vessels is advantageous. Although it is the total fleet capacity that is of paramount importance, the composition of the fleet is also important. It is advantageous to have numerous vessels at one's disposal so that as many offshore installations as possible can be served rapidly. Additionally, it is important that those vessels are relatively large. The reason for this is that large vessels are better suited to cover an installation's total demand in one visit. This gives fast and entire recovery, without too much work concerning the prioritizing of cargo, possible after a long period of bad weather. The use of small vessels in such situations often leads to many revisits and often prioritizing disputes before an installation is entirely recovered.

Given a fixed routing schedule and continuous use of the supply vessels, using a few large vessels rather than several small ones, results in less frequent visits. This can be disadvantageous for several reasons. First, much of the supplies used offshore are expensive rented equipment. Less frequent visits mean higher carrying (interest) costs. Second, as the installations in general have limited storage capacity, frequent visits avoid congestion.

The size of the installations also influences optimal vessel size. The most feared situation offshore is a collision between a large vessel and a small installation. The larger the vessel, the more severe the consequences could be. However, risk is a function of consequence and probability and today the probability is kept low by the strict regulations described earlier in the article. In contrast, using larger vessels means less frequent visits, which again means less manoeuvring out of and into the safety zones of the installations. This would reduce the likelihood of a collision. Notwithstanding, this presupposes that the installations are ready to complete serving of the vessel without delays. If the total time that is spent within the safety zone for a large vessel equals the sum of several shorter times spent by smaller vessels, the advantage of the large vessels disappears.

A factor that could limit the size of the vessels is the capacities of harbours and quays at the supply bases. As far as we know this is not a problem at present. 
It should be noticed that many of the arguments in this section are based on the assumption that the ability to carry deck and bulk cargo is rather similar for all vessels. In reality there are often differences, as mentioned earlier, in particular, related to the ability to carry bulk. To have vessels in a fleet that cannot carry certain types of bulk, do not have an automatic washing system or too few tanks, will give less freedom with regard to planning and reducing the ability to deal with uncertainty. Table 1 summarizes the main points from our discussion.

\section{Searching for the best sailing capacity}

Improvements and innovations that result in a higher speed without any major drawbacks are likely to be rapidly adopted by all ship designers. Today, all supply vessels used on the NCS are designed to sail at approximately the same speed. However, it is tempting to explore the logistics consequences of having vessels that are significantly faster.

It might seem obvious that the main advantage of having faster vessels is that a route can be carried out faster. In some situations we can imagine that this can lead to a reduction of the fleet by one vessel, something that would represent a significant financial saving. However, higher speed at sea usually comes with some major drawbacks that must be considered before we can conclude that faster vessels are beneficial and that savings are realizable.

Due to the laws of physics at sea, low speed is in general the most cost-efficient way to travel. In general, higher speed means significantly higher fuel consumption (Stopford, 1997). Also it is reasonable to assume that a vessel with more powerful machinery will be more expensive to build and charter. How high the fuel consumption will be is also to a large extent determined by the design of the hull. Most supply vessels are designed rather wide and well

Table 1: Summarizing the discussion about fleet configuration

\begin{tabular}{lcc}
\hline The transport capacity for a single vessel & \begin{tabular}{c} 
Basis for dimensioning of individual vessels \\
\cline { 2 - 3 }
\end{tabular} & $\begin{array}{c}\text { The use of } \\
\text { small vessels } \\
\text { large vessels }\end{array}$ \\
\hline Considerations & - & - \\
Low unit transportation cost & - & $\mathrm{X}$ \\
Environmentally friendly & $\mathrm{X}$ & $\mathrm{X}$ \\
Suited to deal with demand uncertainty & $\mathrm{X}$ & $\mathrm{X}$ \\
Suited to deal with weather uncertainty & $\mathrm{X}$ & - \\
Suited to deal with the installations' limited storage capacity & - & $\mathrm{X}$ \\
Low collision impact (consequence) & & - \\
Low exposure time (probability) &
\end{tabular}

318 (C) 2009 Palgrave Macmillan 1479-2931 Maritime Economics \& Logistics Vol. 11, 3, 302-325 
rounded to be able to carry a lot. Such design gives a lot of water resistance and consequently high fuel consumption. In contrast, a slimmer vessel will give lower fuel consumption, but will either be carrying less cargo or be longer. A longer vessel will be more expensive to build because of a heavier hull and it will catch more wind, which is disadvantageous when lying along the side of an installation. This is not only because of the increased collision risk, but also as more engine power is needed to keep the vessel in position; implying higher fuel consumption.

It is also important to consider the time a vessel actually spends sailing. Naturally, this depends on the location of the installations, and the longer the distances the more impact the speed will have on the time it takes to travel the route.

Furthermore, unless dramatic changes are made with today's hull design, high-speed vessels will in general be very weather sensitive. Consequently the transit time will increase. So the benefit of having a high-speed vessel will be limited by how often the weather is good. And this will vary from location to location and during the year (Figure 2).

Of course, a vessel that has the ability to go fast does not have to go fast on a regular basis. However, the possibility to sail even faster than what is possible today will increase the flexibility/ability to meet unforeseen demands, which might trigger shortage costs. An argument that balances this view is that today speed is rarely used actively when transporting urgent demands. The practical reasons for this are that the weather often is not good enough for high speed, the difference between economical and high speed is low and the relevant travelling distances are usually rather short. This makes the time gain very modest combined with the fact that a few minutes gained or lost usually does not matter much.

There are also environmental concerns. Higher fuel consumption gives higher emissions and LNG-powered supply vessels have been introduced in an attempt to decrease emissions. However, this has not proved to be straightforward. The main challenges are that the infrastructure for tanking LNG along the Norwegian coast is not well developed and that the fuel tanks needed onboard the vessels are very large. The latter means that the ability of a supply vessel to take bulk cargo is reduced unless the total size of the vessel is increased, and so far this has been the solution. An important question then is whether the vessels become too large (according to the discussion in the previous section) for many installations or clusters. It does not matter if the emission rate is low if the utilization of the vessel is also low. A useful parameter for addressing this issue could be to measure the amount of emission per transported tonne of supplies.

To summarize this section we can state that the benefits of a significantly higher speed in general will be low mainly because of the weather sensitivity of

(C) 2009 Palgrave Macmillan 1479-2931 Maritime Economics \& Logistics Vol. 11, 3, 302-325 319 
the vessel. Unless this sensitivity is in some way reduced, the usefulness of being able to go at a higher speed in good weather will be low. Consequently the willingness to pay for this capability will be low too.

\section{Searching for the best loading/unloading capability}

As described earlier, it is clear that the capability to load/unload offshore is the main bottleneck in the upstream chain. The important questions are whether it is technically possible to increase this capability, what this will cost and the value of such actions.

Today, designing these vessels so that their manoeuvring abilities are at the best during static operations is already a main priority. The question about whether it is technically possible or not to further improve this capability must be answered by engineers. However, it is the responsibility of the logistician to draw the engineers' attention to the problem and properly describe its logistical magnitude.

As already mentioned, offshore loading/unloading is today governed by strict rules. These rules are based on an assessment of what is considered safe operations given by the present performance level of vessels and cranes. Consequently, it is not unreasonable to assume that these rules can change as supply vessels and cranes become better.

Presently several companies are working with solutions that directly or indirectly could improve the offshore loading/unloading capability (see, for example, ConocoPhillips (2008b) or ODIM (2008)). An example of an initiative that indirectly can lead to improvements, which lately has been given much attention in the business, is the idea of a 'crew-free supply vessel deck'. This initiative is mainly motivated by health and safety reasons and the idea is that it will be beneficial to find a technical solution where the crane hook can be connected to a load carrier without direct physical human involvement. However, it is easy to see that such improvements also would make offshore loading/unloading operations less sensitive to bad weather. Without crew on deck, lifting load carriers in bad weather would be less risky. Also today's 'cherrypicking' rule (as described in the section about loading and unloading capability), will probably be superfluous.

To calculate the costs of such technical improvements aiming to increase the offshore loading/unloading capability must of course be done based on inputs from engineers. It is reasonable to assume that changes related to, for instance, increasing the machinery power of a vessel and/or improving the propulsion arrangements could be costly. Costs can also appear as logistical trade-offs. Using the same example, more thrusters will occupy space in the supply vessel, which otherwise could be used for bulk transport. In other 
words, some of the carrying capacity is traded in for a better capability to deliver in bad weather. When considering changes that bring up trade-off issues, inputs from logisticians are needed.

However, there is considerable benefit in reducing the bottleneck problem. Higher delivery regularity will significantly reduce uncertainty. The main advantage of this is that the whole supply situation will be more predictable together. In addition, this will release transport capacity. Planning and scheduling will be easier and a more cost-efficient and an environmentally friendly fleet could be realizable. A more predictable servicing of the routes would also lead to a higher service level for the installations. This would have many positive effects. The most important one would be that the risk for triggering shortage costs will be reduced. However, positive effects like a decreased need for having back-up equipment onboard together with obtaining a more streamlined flow of return cargo will be important improvements. In general, a less congested installation is assumed to represent a less risky work environment too.

If the loading/unloading capability for only one category of supplies becomes significantly less weather sensitive, some of the advantages of simultaneous transport could disappear. It would then be interesting to evaluate the logistical consequences of moving in the direction of more specialization by having a more pure bulk or deck cargo vessel in a fleet. The obvious advantage will be that the less weather sensitive category can be supplied with better regularity. It is even possible that better regularity would make it more relevant to consider vendor managed inventories (Toth and Vigo, 2002) for certain types of supplies. Besides this, the ship designers we interviewed indicated that the design of more purely dedicated vessels could make the construction of vessels with better sea behaviour possible. This could again affect the sailing and the offshore loading/unloading capability. How the introduction of such a vessel in a fleet will affect the efficiency of the logistics with regard to scheduling and routing is not obvious. We suggest that more research on this subject is required.

To sum up this section, we can claim that the limitation of the supply vessel to deliver in bad weather represents the most significant bottleneck in the upstream chain. When looking at the other discussed features of a supply vessel, carrying capacity and sailing capability, it is also clear that the determination of these is to a large extent affected by/deduced from this bottleneck.

\section{Conclusions and Further Research}

To summarize we can say that the main logistics challenge for supply vessels is their limited ability to load/unload offshore. To find ways to reduce the 
consequences of bad weather stands out as the most important challenge in the upstream chain. Besides this, the demand uncertainty makes the logistics problems significantly harder to solve and thereby constitutes a major challenge. It is important to understand that there are usually financial trade-offs between actions that could reduce uncertainty and the costs of running a logistics system under uncertainty.

To regard supply vessels separately, as we have done in this article, is obviously not sufficient if the goal is to determine the most cost-efficient allocation of resources to improve the logistics. In a perfect world, an extra cent should have the same effect wherever it is used. In the problem described, the oil companies have to a large extent the opportunity to obtain this, because of their significant power in the supply chain. If for reasons of simplicity we narrow the focus down to the supply vessel and its closest environment, the question is whether resources should be spent on the vessel itself, the cranes on the installation, container design or to improve the planning capability. For the latter, confer Aas and Wallace (2009). To answer this question properly, thorough knowledge about the different elements and their interaction is necessary. Consequently, several basic logistics analyses, like the one here, must be carried out to create a good foundation for decision-making.

A thoroughly understanding of one's own logistics is also crucial for being able to determine the best sourcing strategy. As we have seen, supply vessels are usually chartered and the length of the charters is important for how tailormade the vessels can become. When ordering a vessel, the shipowner must consider its suitability with regard to different customers and different geographical locations. Due to this, many of the vessels built become rather similar and are not customized to satisfy the needs of a particular cluster. The newest and most innovative vessels used on the NCS are built for long-term charters. And even these cannot be characterized as particularly radical or dissimilar compared with the mainstream vessels, at least from a pure logistical perspective. As one of the interviewees in a ship design company put it: the development in the last twenty years cannot be characterized as dramatic, it has merely been characterized by a series of small improvements on the existing concept. It is reasonable to assume that a demand for 'similar' and 'traditional' vessels affects what is developed and promoted by ship design companies. According to Schneekluth and Bertram (1998), such practice could lead to the building of ships, which are suboptimal. Changes such as a better understanding of the upstream logistics, technological developments, more focus on environmental concerns and an increased number of mature areas could indicate a need for vessels that are quite different from those of today.

For the oil companies, the relevant choice is whether to take a tailor-made vessel on a long-term charter, a vessel that better suits their needs or to charter 
a mainstream vessel that is not as suited, but cheaper to charter. A logistics analysis must be carried out to understand whether and to what extent a vessel is suited or not, and to determine the financial advantages and disadvantages of this. In other words, the choice of vessel and chartering policy must be based on knowledge about the supply vessel market and its logistics. It is important not to act in the market in a way that restrains the development of more suited/ better vessels. It is also a fact that a heterogeneous fleet often will perform better than a homogeneous fleet, however, 'different' vessels that make such tactical capacity adjustments possible will not be built, before some of the actors in the market see the value of them.

Unfortunately for the oil companies, their supply challenge is rather complex mainly because of the existing uncertain factors and the total complexity of their logistics system. Furthermore, the complexity seems to have increased significantly in the last few decades in accordance with the expansion of offshore developments. This means that the logistics analysis becomes complex and finding ways to improve the logistics system is not straightforward.

Until now, research on the logistics problems has been scarce and we believe that it would be beneficial for all parties to intensify research efforts. The formal logistics knowledge in the oil companies on the NCS is rather low, so it is likely that something is to be learnt from a more theoretical approach. Furthermore, as the logistics costs are very high, even small improvements could justify the cost of an extended research effort. It could also be that more research leads to insights that again bring more radical changes in the upstream chain. It is also likely that academics have something to learn from the practical execution of a logistics system that contains challenges that are known to be difficult to approach theoretically.

We hereby suggest more research concerning the elements in the upstream chain and their interaction. When a sufficient level of basic knowledge is obtained, research that addresses the logistic system efficiency is the natural next step.

\section{Acknowledgements}

The authors acknowledge the contributions from StatoilHydro employees companywide, who have indirectly contributed significantly to this article by supporting the many master's projects at Molde University College over the past 5 years. They also thank Ulstein Design, Solstad Offshore, R.S. Platou Offshore, and in particular the personnel at StatoilHydro's supply base in Kristiansund for valuable contributions. 


\section{Notes}

1 The average rent for supply vessels in the category over $762 \mathrm{~m}^{2}$ was for 2007 approximately $€ 36000$ per day, Offshore Shipbrokers Limited (2008).

$21 \mathrm{knot}=1$ nautical mile/hour $=1852 \mathrm{~m} /$ hour.

\section{References}

Aas, B. and Wallace, S.W. (2009) Management of Logistics Planning. Molde, Norway: Molde University College. Working paper, No. 1.

Aas, B., Buvik, A. and Cakic, D.J. (2008) Outsourcing of logistics activities in a complex supply chain: A case study from the Norwegian oil and gas industry. International Journal of Procurement Management 1(3): 280-296.

Aas, B., Gribkovskaia, I. and Halskau, $\varnothing$. (2007) Routing of supply vessels to petroleum installations. International Journal of Physical Distribution \& Logistics Management 37(2): 164-179.

Alderton, P.M. (1995) Sea Transportation - Operation and Economics. Surrey, UK: Thomas Reed Publications.

Barret, D. (2005) The Offshore Supply Boat Sector, Sector Note, New York, USA: Fortis Bank.

Benito, G.R.G., Berger, E., de la Forest, M. and Shum, J. (2003) A cluster analysis of the maritime sector in Norway. International Journal of Transport Management 1(4): 203-215.

Bourbon Offshore Norway. (2008) Homepage Bourbon Offshore Norway, http://www.bourbon-offshore.no, accessed 18 February 2008.

Christiansen, M., Fagerholt, K. and Ronen, D. (2004) Ship routing and scheduling: Status and perspectives. Transportation Science 38(1): 1-18.

Christopher, M.G. (2000) The agile supply chain: Competing in volatile markets. Industrial Marketing Management 29(1): 37-44.

ConocoPhillips. (2008a) Homepage ConocoPhillips in Norway, http://www.conocophillips.no/ read.aspx? $\mathrm{db}=$ INTERNET/MAIN.NSF, accessed 27 February 2008.

ConocoPhillips. (2008b) Homepage ConocoPhillips in Norway: Optimizing Offshore Crane Lifts, http://www.conocophillips.no/read.aspx?db = INTERNET/MAIN.NSF\&uid = BA4B3AE33CD27871 C12573EF003F0DAB\&muid =0324106756E717F5C1256D0400758515, accessed 27 February 2008.

DNV. (2008) Homepage DNV UK, http://www.dnv.co.uk, accessed 10 February 2008.

Eidesvik Shipping. (2008) Homepage Eidesvik Shipping, http://www.eidesvik.no/index.htm, accessed 10 February 2008.

Fagerholt, K. and Lindstad, H. (2000) Optimal policies for maintaining a supply service in the Norwegian sea. Omega 28(3): 269-275.

Gibson, V. (2007) The History of the Supply Ship. Aberdeen, UK: La Madrila Press.

Gribkovskaia, I., Laporte, G. and Shlopak, A. (2007) A tabu search heuristic for a routing problem arising in the servicing offshore oil and gas platforms. Journal of the Operational Research Society, doi: 10.1057 /palgrave.jors.2602469.

Hyne, N.J. (2001) Nontechnical Guide to Petroleum Geology, Exploration, Drilling and Production, 2nd edn. Oklahoma, USA: Penn Well Corp.

IOCENTER (Centre for Integrated Operations in the Petroleum Industry). (2008) Homepage IOCENTER, http://www.ntnu.no/iocenter, accessed 15 February 2008.

Lamming, R.C. (1993) Beyond Partnership: Strategies for Innovation and Lean Supply. Hemel Hempstead, UK: Prentice-Hall.

Ministry of Petroleum and Energy. (2004) Om petroleumsvirksomheten, St.meld. nr. 38 (2003-2004). Oslo, Norway: The Ministry.

324 (C) 2009 Palgrave Macmillan 1479-2931 Maritime Economics \& Logistics Vol. 11, 3, 302-325 
Norwegian Petroleum Directorate. (2007) FACTS - The Norwegian Petroleum Sector 2007. Oslo, Norway: Ministry of Petroleum and Energy and the Norwegian Petroleum Directorate.

ODIM ASA. (2008) ODIM ABS ${ }^{\mathrm{TM}}$ - Automatic Bulk Hose System, http://www.odim.com/Files/ Produktark/ODIM\%20ABCS.pdf, accessed 26 January 2008.

Offshore Shipbrokers Limited. (2008) North Sea Market Report - January 2008, http://ifb. offshore-shipbrokers.co.uk/reports/0108.pdf, accessed 26 February 2008.

R.S Platou Offshore A.S. (2008) The Platou Report 2008, http://www.platou.com/loadfileservlet/ loadfiledb?id = 1205311719484PUBLISHER\&key = 1205499801725, accessed 20 March 2008.

Ritchie, G. (2007) Practical Introduction to Anchor Handling and Supply Vessel Operations. London, UK: Clarkson Research Services Limited.

Schneekluth, H. and Bertram, V. (1998) Ship Design for Efficiency and Economy, 2nd edn. Oxford, UK: Butterworth and Heinemann; Reed Elsevier.

Solstad Offshore ASA. (2008) Homepage Solstad Offshore: NORMAND SKIPPER, http://www. solstad.no/web/internet.nsf/(docs)/FB120A040FB6CB40C125730000469E04?opendocument\& cat $1=$ Fleet $\&$ cat $2=$ Platform \%20Supply, accessed 28 February 2008.

StatoilHydro ASA. (2008) Homepage StatoilHydro ASA, http://www.statoilhydro.com/en/Pages/ default.aspx, accessed 2 February 2008.

Stopford, M. (1997) Maritime Economics, 2nd edn. London and New York: Routledge Taylor \& Francis Group.

SWIRE. (2008) Homepage SWIRE, http://www.swire.no, accessed 2 February 2008.

The Norwegian Oil Industry Association (OLF). (2008) Homepage OLF: Guidelines for the Safe Management of Offshore Supply and Anchor Handling Operations (NWEA), http://www.olf.no/ hms/dokumenter/nwea_common_guidelines/?30111, accessed 8 January 2008.

Toth, P. and Vigo, D. (2002) The Vehicle Routing Problem. Philadelphia, PA: Siam.

Ulstein Group. (2008) Homepage Ulstein Group: PX10, http://www.ulsteingroup.com/kunder/ ulstein/cms66.nsf/pages/shipdesign.htm?open\&qnfl = flash\#shipdesign/p-series/ulsteinpx105/ product/ulsteinpx105.itm, accessed 9 January 2008.

Vik-Sandvik. (2008) Viking Avant, http://www.vik-sandvik.com/files/VikSandvik_pdf/VikingAvant .pdf, accessed 20 February 2008. 